\title{
Intranasal Losartan Decreases Perivascular Beta Amyloid, Inflammation, and the Decline of Neurogenesis in Hypertensive Rats
}

\author{
Henning J. Drews ${ }^{1} \cdot$ Konstantin Yenkoyan $^{2,3}$ - Ali Lourhmati ${ }^{1}$ - Marine Buadze ${ }^{1}$. Daniela Kabisch $^{1}$. \\ Stephan Verleysdonk ${ }^{4}$ - Stefan Petschak ${ }^{1}$ - Sandra Beer-Hammer ${ }^{5}$ - Tigran Davtyan ${ }^{6}$ • William H. Frey II ${ }^{7}$ \\ Christoph H. Gleiter ${ }^{1}$ • Matthias Schwab ${ }^{1,2,3,8,9} \cdot$ Lusine Danielyan $^{1,2,3}$ (D)
}

Published online: 22 February 2019

(C) The American Society for Experimental NeuroTherapeutics, Inc. 2019

\begin{abstract}
The contribution of the local angiotensin receptor system to neuroinflammation, impaired neurogenesis, and amyloid beta (A $\beta$ ) accumulation in Alzheimer's disease (AD) and in hypertension is consistent with the remarkable neuroprotection provided by angiotensin receptor blockers (ARBs) independent of their blood pressure-lowering effect. Considering the causal relationship between hypertension and $\mathrm{AD}$ and that targeting cerebrovascular pathology with ARBs does not necessarily require their systemic effects, we tested intranasal losartan in the rat model of chronic hypertension (spontaneously hypertensive strokeprone rats, SHRSP). Intranasal losartan at a subdepressor dose decreased mortality, neuroinflammation, and perivascular content of $\mathrm{A} \beta$ by enhancing key players in its metabolism and clearance, including insulin-degrading enzyme, neprilysin, and transthyretin. Furthermore, this treatment improved neurologic deficits and increased brain IL-10 concentration, hippocampal cell survival, neurogenesis, and choroid plexus cell proliferation in SHRSP. Losartan $(1 \mu \mathrm{M})$ also reduced LDH release from cultured astroglial cells in response to toxic glutamate concentrations. This effect was completely blunted by IL-10 antibodies. These findings suggest that intranasal ARB treatment is a neuroprotective, neurogenesis-inducing, and A $\beta$-decreasing strategy for the treatment of hypertensive stroke and cerebral amyloid angiopathy acting at least partly through the IL-10 pathway.
\end{abstract}

Key Words Angiotensin - Angiotensin receptor blocker · Hemorrhagic stroke · Intranasal · Cerebral amyloid angiopathy · Alzheimer's disease

Henning J. Drews and Konstantin Yenkoyan contributed equally to this work.

Lusine Danielyan

lusine.danielyan@med.uni-tuebingen.de

1 Department of Clinical Pharmacology, University Hospital of Tuebingen, Auf der Morgenstelle 8, 72076 Tuebingen, Germany

2 Departments of Biochemistry and of Clinical Pharmacology, Yerevan State Medical University, 0025 Yerevan, Armenia

3 Neuroscience Laboratory, Yerevan State Medical University, 0025 Yerevan, Armenia

4 Interfaculty Institute of Biochemistry (IFIB), Eberhard Karls Universität Tübingen, 72076 Tuebingen, Germany
5 Department of Pharmacology and Experimental Therapy and Interfaculty Center of Pharmacogenomics and Drug Research (ICePhA), University of Tuebingen, 72074 Tuebingen, Germany

6 Analytical Laboratory Branch of E. Gabriyelian Scientific Center of Drug and Medical Technology Expertise of Ministry Health of Armenia, 0051 Yerevan, Armenia

7 Center for Memory \& Aging, HealthPartners Institute, St. Paul, MN, USA

8 Dr. Margarete Fischer-Bosch-Institute of Clinical Pharmacology, 70376 Stuttgart, Germany

9 Department of Pharmacy and Biochemistry, University of Tuebingen, 72076 Tuebingen, Germany 


\section{Introduction}

The relationship between Alzheimers disease (AD) and hypertension is based not only on the notion that the latter is one of the major risk factors for $\mathrm{AD}$ but also on common factors involved in the respective disease pathologies. In both chronic hypertension and $\mathrm{AD}$, neuroinflammation, generation of amyloid beta $(A \beta)$ fragments, impaired neurogenesis, and cholinergic and synaptic dysfunction are all components of brain pathology (for review, see [1, 2]).

The local renin-angiotensin system (RAS) in the CNS has been proposed to play a critical role in the pathogenesis of numerous CNS disorders. This suggestion is mainly based on the beneficial effects of antihypertensive angiotensin receptor type 1 (AT1R) blockers (ARBs) in different experimental models of brain disorders such as stroke [3], AD [4], and Parkinson's disease [5]. The therapeutic potential of ARBs and angiotensin-converting enzyme (ACE) inhibitors on cognitive function has been demonstrated in several clinical trials (for review, see [6]) showing greater cognition-improving effects with ARBs. Recent work by Bhat et al. demonstrated that oral low-dose candesartan increased hippocampal neurogenesis and suppressed neuroinflammation in a renal artery occlusion model of hypertension independent of any effect on blood pressure (BP) [7].

In contrast to systemic administration, intranasal (IN) delivery to the upper third of the nasal cavity facilitates observation of the more targeted effects of ARBs on the CNS in the absence of their systemic action. IN delivery allows therapeutics to bypass the blood-brain barrier and targets delivery to the CNS of substances [8] and therapeutics [8-11], viral particles [12], and cells [13] along the olfactory and/or trigeminal neural pathways. The successful demonstration that intranasal insulin safely improved memory in patients with $\mathrm{AD}$ or mild cognitive impairment in multiple human clinical trials without altering the blood levels of either insulin or glucose indicates the potential of intranasal therapeutics for targeting the brain to treat neurodegenerative disorders in humans [14].

Our previous work demonstrated that intranasal losartan (IN-losartan) is a potent anti-inflammatory treatment in a transgenic model of AD [4]. IN-losartan decreased inflammatory cytokines and upregulated IL-10 in the blood serum of APP/PS1 transgenic mice. However, whether a subdepressor dose of intranasal ARB may also decrease brain inflammation and consequently reduce mortality and improve neurologic outcome in chronic malignant hypertension remained unexplored. Here, we hypothesized that at least some of the protective effects of ARBs may be due to upregulation of brain IL-10 which is a strong anti-inflammatory [15] and cytoprotective factor [16]. IL-10 is upregulated in the brain by low-dose systemic ARB treatment in the renal artery occlusion model of hypertension [7]. Therefore, in the present study, we investigated the influence of low-dose IN-losartan on neurologic outcome, neurogenesis, and inflammatory response in a rat model of chronic severe hypertension.

While the anti-inflammatory and neurogenesis-inducing effects of low-dose systemically applied ARBs have been extensively described in various models of brain degeneration including $\mathrm{AD}$, multiple sclerosis, ischemic stroke, and Parkinson's disease [4, 5, 17], low-dose intranasal ARBs have been tested only in models of $\mathrm{AD}[4,18]$. Their effect on the hypertension-induced increase in cerebral amyloid content remained yet unexplored. Cerebral amyloid angiopathy (CAA) has been shown to coexist with hypertension in patients with intracerebral hemorrhage [19] and in spontaneously hypertensive stroke-prone rats (SHRSP) [20]. Aside from the contradictory findings that ARB may or may not influence the brain content of $A \beta$ in transgenic models of $\operatorname{AD}[18,21]$ and can improve cerebral vessel disease in hypertensive patients and animals $[22,23]$, the question of whether the $A \beta$ lowering effect of ARBs is associated with the BP decrease remained unanswered. Here, we investigated whether, in addition to its neuroprotective and anti-inflammatory properties, a targeted delivery of an ARB losartan to the brain by intranasal administration can improve the overall clearance and perivascular deposition of $A \beta$ in a chronic model of malignant hypertension (SHRSP).

\section{Methods}

\section{Animals}

All animal procedures were carried out in accordance with the ethical guidelines for use of laboratory animals EU Directive 2010/63/EU and were approved by the administration office of the local governmental authority (Regierungspräsidium Tübingen) and by the Ethics committee of Yerevan State Medical University. Male 7-week-old SHRSP (Charles River, Sulzfeld, Germany) were given salt-rich (2\%) chow kindly provided and partially sponsored by Altromin (Lage, Germany) and $1 \% \mathrm{NaCl}$ drinking water solution ad libitum.

A $\beta 42$ intracerebroventricular (injection) was performed on 12- to 15-month-old Sprague Dawley male rats weighing 220 to $300 \mathrm{~g}$.

\section{Measurement of Systolic Blood Pressure}

Systolic blood pressure (BP) was measured using the tail-cuff method with a BP analyzer (Hugo Sachs, March-Hugstetten, Germany) as described elsewhere [24]. After a training period of 5 consecutive days, systolic BP was monitored 6 times prior to assignment of animals into the groups (once a week) and 5 times after assignment during the drug treatment period (once a week) $30 \mathrm{~min}$ and $24 \mathrm{~h}$ after losartan administration. 


\section{Intranasal Losartan Treatment}

On the 47th day of their salt-loaded diet and prior to stroke onset, the rats were assigned into groups ( $n=9$ in each) in a way that the mean systolic BP in both groups remained equal. Losartan and vehicle were administrated every second day between 6 and 8 a.m. for 35 days starting at day 48 of the experiment. For intranasal (IN) application, losartan $(0.24 \mathrm{mg} /$ animal) was dissolved in $24 \mu \mathrm{L}$ PBS. Controls received the same volume of sterile PBS only. The rats were held with a hand grip that allowed the animals to recline on their backs while immobilizing the skull, and the nose drop containing the substance was carefully placed on one nostril, allowing it to be snorted essentially. The rats received twice for each nostril alternate applications (left-right) of gradually applied $6-\mu \mathrm{L}$ drops containing losartan or PBS (the second set of rightleft applications was performed $2 \mathrm{~min}$ after the first set). After IN treatment, the rat was kept on its back with its head reclined for $20 \mathrm{~s}$.

Losartan and PBS, respectively, were applied IN during the 5 weeks every other day. During the whole experiment, BP was measured once a week. Neurological status (every other or third day), survival, and weight (every fourth day) were monitored as well. After 5 weeks of drug treatment, the rats were sacrificed under ketamine anesthesia (ketamine, $100 \mathrm{mg} / \mathrm{kg}$, i.p.; Delta Select, Pfullingen, Germany). The brain hemispheres were dissected and stored at $-80^{\circ} \mathrm{C}$ for further analyses as described below.

\section{Assessment of Neurological Deficits}

The neurologic score was determined by the outcome of several motor and behavioral tests adapted from Yamori et al. and Albert et al. [25, 26]. Sensorimotor function and sense of balance in a complex movement were assessed with the modified balance beam test [27-29] by adding a rate- and direction-changing rotation of the rod. The rats were placed lengthwise on a wooden rod $2.5 \mathrm{~cm}$ in diameter (length, $145 \mathrm{~cm}$ ). After $3 \mathrm{~s}$, the rod was rotated 2 full revolutions at a speed of $16 \mathrm{~s}$ per revolution. Thereafter, the rotation was stopped for $3 \mathrm{~s}$ and continued backwards at the same rate. Animal performances were classified according to a scoring system ranging from 0 to 3 ( 0 , task performed without any difficulty; 1 , rat fell off the rotating rod while struggling to remain on top; 2, rat fell off the rod at the onset of rotation without any resistance; 3 , rat could not be placed on the static rod). The best of 3 runs was integrated into the total neurological score.

Further, we monitored forelimb flexion when the rat walked on its forelimbs while being held by the tail [27, 30-32]. The animals were held up by the tail approximately $50 \mathrm{~cm}$ above the cage for $5 \mathrm{~s}$, and forelimb outstretching was observed. Then the rats were lowered until the forelimbs reached the wired cage top. The animals were observed while walking across the cage top. Any asymmetry in forelimb outstretching was added as +1 to the result of the rotating rod test.

Behavioral deficits, such as aggression, agitation, and apathy [33], were assessed by placing a gloved hand (the glove was impregnated with the smell of various rats) approximately $5 \mathrm{~cm}$ in front of the animal and allowing it to be explored for about $5 \mathrm{~s}$. A curious movement towards the glove followed by sniffing was rated as 0 reflecting explorative activity, lack of anxiety, aggression, and apathy. Aggression towards the glove (as previously described by Albert et al. [26]), agitation (escape movements from the glove), or apathy reflected by lack of interest to explore the glove received 1 point.

All rats underwent a training period of 9 runs per day on 3 consecutive days prior to the first recorded balance test. The limb flexion and behavioral assessment did not require a preceding training.

Neurological scores were assessed every other or third day, resulting in a total of 32 measurements.

\section{Preparation of $A \beta 42$ Peptide}

A $31-42$ peptide (Sigma-Aldrich, St. Louis, MO, USA) was dissolved in sterile bidistilled water at a concentration of $1 \mathrm{mg} /$ $\mathrm{mL}$, aliquoted, and stored at $-18{ }^{\circ} \mathrm{C}$. "Aging" of the peptide was performed by incubation at $37^{\circ} \mathrm{C}$ for 4 days before the surgery. Light microscopic observation demonstrated the existence of both fibril-like structures and globular aggregates under Congo red staining (data not shown).

\section{Stereotactic Injection of $A \beta 42$}

The animals were anesthetized with Nembutal $(40 \mathrm{mg} / \mathrm{kg})$, positioned in a stereotaxic frame, and a midline sagittal incision was made in the scalp. Holes were drilled in the skull over the lateral ventricles using the following coordinates: $0.8 \mathrm{~mm}$ posterior to the bregma and $1.5 \mathrm{~mm}$ lateral to the sagittal suture according to the stereotaxic atlas of Paxinos and Watson [34]. All injections were made using a $10-\mu \mathrm{L}$ Hamilton syringe equipped with a $26 \mathrm{~S}$ gauge needle. The needle of the microsyringe was placed $3.8 \mathrm{~mm}$ beneath the surface of the brain. The animals were injected bilaterally with $3 \mu \mathrm{L}$ of sterile doubledistilled water (vehicle-treated) or $3 \mu \mathrm{L}$ of aggregated A $\beta 1-42$ solution into each cerebral lateral ventricle at a rate of $1 \mu \mathrm{L} / \mathrm{min}$ using the peristaltic pump. The control and $A \beta 1-42$ groups were sacrificed at the 90th day of the experiment, and selected brain regions (hippocampus and SVZ) were dissected according to the stereotaxic atlas of Paxinos and Watson [34]. 


\section{Flow Cytometry of Hippocampal and SVZ Cells}

The hippocampal and SVZ cells were fixed in PBS, containing $0.1 \%$ paraformaldehyde solution, $1 \%$ bovine serum albumin, and cocktail of protease inhibitors (Roche Diagnostics, Mannheim, Germany), $\mathrm{pH}=7.4$.

Fixed cells were incubated with BD FACS Permeabilizing Solution (BD Biosciences, San Jose, $\mathrm{CA})$ and intracellularly stained with primary monoclonal antibodies against nestin (Abcam, Cambridge, UK), VEGF (Abcam), and polyclonal Sox2 antibody (Abcam), followed by incubation with biotinylated anti-mouse and anti-rabbit secondary antibodies (R\&D Systems, Minneapolis, MN) and fluorescent labels (Streptavidin FITC, R\&D Systems, or Mouse IgG1 PE, R\&D Systems). After each step of incubation, the cells were washed with PBS $(\mathrm{pH}=7.4)$, rotated end over end, and centrifuged at $900 \times \mathrm{g}$ for $10 \mathrm{~min}$ at $4{ }^{\circ} \mathrm{C}$.

Stained cells were analyzed by FACS Calibur ${ }^{\mathrm{TM}}$ instrument with CellQuest (Becton Dickinson, Franklin Lake, NJ) software. A small portion of the fixed cells was incubated without antibodies to gate cells according to their light scattering characteristics. Another portion of the fixed cells was mixed with streptavidin FITC or mouse IgG1 PE conjugates without primary antibody to set the maximum threshold for nonspecific binding.

\section{Quantification of $\beta$-Tubulin III mRNA}

For the determination of $\beta$-tubulin III mRNA by quantitative polymerase chain reaction (qPCR), $500 \mathrm{ng}$ of total RNA, isolated from brain homogenates by RNeasy Lipid Tissue Midi Kit (Qiagen, Hilden, Germany), was reverse-transcribed with AMV reverse transcriptase (PEQ-Lab, Erlangen, Germany), random primers (Promega, Mannheim, Germany), and oligo $(\mathrm{dT})_{15}$ primer (Promega). Real-time PCR assays were performed using the LightCycler ${ }^{\circledR}$ FastStart DNA Master SYBR Green I system (Roche Diagnostics) in the Light Cycler® 2.0 instrument. PCR was carried out with $2 \mu \mathrm{L}$ of reverse transcription product in $10 \mu \mathrm{L}$ PCR mix for a total of 45 cycles. After $10 \mathrm{~min}$ at $95^{\circ} \mathrm{C}$ for polymerase activation, 45 cycles of PCR followed (denaturation at $95^{\circ} \mathrm{C}$ for $5 \mathrm{~s}$, annealing at $63{ }^{\circ} \mathrm{C}$ for $10 \mathrm{~s}$, extension at $72{ }^{\circ} \mathrm{C}$ for $9 \mathrm{~s}$ ). A melting curve analysis was subsequently performed to confirm the presence of a uniform PCR product. The primers employed are listed in Suppl. Tab. 1. The data are shown as relative expression ratios with respect to the mean of the normoxic control.

\section{RNA Isolation and qPCR from Astroglial Primary Culture}

Cells were lysed with RLT-Buffer, and for isolation, the RNA Mini Kit (Qiagen) was applied according to the manual.
Reverse transcription of RNA was performed with the Transcriptor High Fidelity cDNA Synthesis Kit (Roche) according to the protocol provided. For quantitative PCR, $50 \mathrm{ng}$ cDNA was used.

Quantitative PCRs were performed with a LightCycler 480 (Roche) with a primary 5 -min denaturation step at $95^{\circ} \mathrm{C}, 45$ cycles with $10 \mathrm{~s}$ denaturation at $95^{\circ} \mathrm{C}, 10 \mathrm{~s}$ annealing at $60^{\circ} \mathrm{C}$ and $10 \mathrm{~s}$ elongation at $72^{\circ} \mathrm{C}$, and a melting curve as the final step with $5 \mathrm{~s}$ at $95{ }^{\circ} \mathrm{C}$ and $1 \mathrm{~min}$ at $65^{\circ} \mathrm{C}$. PCR results were analyzed by normalizing the expression of each target gene to the expression of the housekeeping gene $\beta$-actin in each sample.

\section{Western Blot Analyses}

Western blotting was performed using protein lysates from the homogenates of the SHSPR brain hemispheres. Protein concentrations were measured using the Bradford assay. For each lane, $50 \mu \mathrm{g}$ of proteins was subjected to sodium dodecyl sulfate polyacrylamide gel electrophoresis (SDS-PAGE) in a $12.5 \%$ gel and transferred to polyvinylidene fluoride (PVDF) membranes by tank blotting. Membranes were blocked in $0.66 \%(v / w)$ I-Block in PBS (Tropix, Applied Biosystems, Weiterstadt, Germany) for $1.5 \mathrm{~h}$ and were then incubated at $4{ }^{\circ} \mathrm{C}$ overnight with antibodies against AT1-R (dilution 1:500, Abcam), AT2-R (1:1200, Abcam), NeuroD1 (dilution 1:500, GeneTex Inc., Irvine, CA), IL-10 (1:2000, Abcam), Stat3 (1:1:500, BD, Franklin Lakes, NJ), TNF- $\alpha$ (1:2500, Acris, Hiddenhausen, Germany), and GAPDH (loading control, 1:1000, Millipore Merck, Darmstadt, Germany). For visualization of antibody binding, membranes were incubated for $2 \mathrm{~h}$ at room temperature with alkaline phosphataseconjugated goat anti-rabbit or anti-mouse secondary antibodies (AB Applied Biosystems, Waltham, MA), diluted 1:10,000 in PBS, and thereafter exposed to CDP-Star (Tropix) as chemoluminescence substrate for $1 \mathrm{~h}$ in the dark room. Signal intensities were recorded using a CCD camera system. Antibodies employed in Western blot and immunofluorescence analyses are provided in Suppl. Tab. 3.

\section{Immunofluorescence Analyses}

Horizontal sections (10 $\mu \mathrm{m}$ thickness) were taken from brain hemispheres of SHSPR. Serial sections used for counting of terminal deoxynucleotidyl transferase nick end labeling (TUNEL) and Proliferating Cell Nuclear Antigen (PCNA)positive cells were taken from the entire hippocampus and lateral ventricle. After fixation with $-20{ }^{\circ} \mathrm{C}$ cold methanol, the brain sections were rinsed with PBS and incubated with primary antibodies diluted in PBS for $1 \mathrm{~h}$ at room temperature (RT). The sections were washed twice with PBS and incubated in the dark with one of the following combinations of secondary antibodies: fluorescein isothiocyanate (FITC)- 
conjugated goat anti-rabbit IgG and Cy3-conjugated goat antimouse IgG or goat anti-rabbit IgG (all from Jackson ImmunoResearch, Newmarket, UK), for $1 \mathrm{~h}$ at RT. After washing twice with PBS containing $0.1 \%(v / v)$ Triton X-100 (Sigma, Taufkirchen, Germany), samples were mounted with Vectashield medium (Vector Laboratories Burlingame, CA) containing 4',6 diamidino-2-phenylindole (DAPI) and assessed by fluorescence microscopy.

\section{TUNEL Staining}

A terminal deoxynucleotidyl transferase (TdT) nick end labelling (TUNEL) kit (In Situ Cell Death Detection Kit, Fluorescein, Roche Diagnostics) was used to detect apoptotic cells in the brain sections of SHRSP. TUNEL staining was then combined with immunofluorescent staining of GFAP. For TUNEL labelling, $50 \mu \mathrm{L}$ of the stock solution containing $450 \mu \mathrm{L}$ "lab solution" and $50 \mu \mathrm{L}$ "enzyme solution" was applied to each brain section and incubated in a dark, moist box for $1 \mathrm{~h}$. After washing with PBS for $5 \mathrm{~min}$, GFAP staining was performed using GFAP mouse monoclonal antibodies and goat anti-mouse $\mathrm{Cy}-3 \mathrm{IgG}$ as described above. The controls for the TUNEL staining were incubated with "lab solution" and secondary antibody only.

\section{Preparation of Rat Brain Homogenates}

The brains were processed in ice-cold lysis buffer ( $300 \mathrm{mmol} / \mathrm{L} \mathrm{NaCl}, 50 \mathrm{mmol} / \mathrm{L}$ Tris, $2 \mathrm{mmol} / \mathrm{L} \mathrm{MgCl}_{2}$, $0.5 \%$ NP40, containing a "Complete Protease Inhibitor Tablet" from Roche Diagnostics at a ratio of 1:5 (tissue weight/buffer volume)). The tissue was disrupted using a Micro Dismembrator II (B.Braun, Melsungen, Germany) at maximal amplitude for $30 \mathrm{~s}$ in a teflon container which had been precooled with liquid nitrogen. Thereafter, homogenates were clarified by centrifugation at $1500 \times g$ and $4{ }^{\circ} \mathrm{C}$ for $15 \mathrm{~min}$. The supernatant was divided into aliquot parts and either stored frozen at $-80{ }^{\circ} \mathrm{C}$ or immediately analyzed for amyloid- $\beta$ (Abeta), angiotensin II, and inflammation-related cytokines. The protein quantification was performed using the BIO-Rad (München, Germany) DC Protein Assay according to the manufacturer's manual.

\section{Determination of $A \beta 40$ and $A \beta 42$}

$A \beta 40$ and $A \beta 42$ in rat brain homogenates were quantified using the Amyloid Beta Magnetic Bead Panel - Multiplex Assay Merck KGaA, Darmstadt, Germany. For this, reagent blank, test sample blank, 7 standards (range 3.8-2470 pg/mL), controls, and samples were measured according to the manufacturer's manual. Results were expressed as picograms Abeta/milliliter brain tissue lysate.

\section{Determination of Angiotensin II}

Angiotensin II was determined in rat brain homogenates using an enzyme immunoassay kit (A05880, SPIbio, Montigny le Bretonneux, France) containing monoclonal angiotensin antibody immobilized on a 96-well plate. Angiotensin II concentration in the brain homogenate samples was determined using linear curve fitting. Results are shown in picograms angiotensin II/milligram protein. Brain homogenates from agematched male Wistar rats $(n=5)$ served as the normotensive controls.

\section{Determination of Cytokines}

The cytokine measurement by multiplex analysis was performed as described elsewhere [4]. Briefly, $50 \mu \mathrm{L}$ cell culture medium was removed from a dish and used for detection of interleukin-1-beta (IL-1- $\beta$ ), IL-2, IL-4, IL-5, IL-6, IL-10, IL12 (p70), granulocyte-monocyte-colony-stimulating factor (GM-CSF), interferon-gamma (IFN- $\gamma$ ), and tumor necrosis factor-alpha (TNF- $\alpha$ ). The quantification of these cytokines was performed with a Beadlyte Multi-Cytokine BeadmasterTM Kit (Upstate, Lake Placid, NY) and a Luminex-100 system (Luminex Corporation, Austin, TX) according to the manufacturer's instructions. The results are reported in micrograms per milliliter.

\section{Measurement of LDH Release from Rat Astroglial Primary Cultures}

Astroglial primary cultures (APC) were prepared from brains of newborn Wistar rats (Charles River). The isolated cell suspension was centrifuged at $300 \times g$ for $8 \mathrm{~min}$ and transferred to $15 \mathrm{~mL}$ supplemented cell culture medium. The cells were cultured with Dulbecco's modified Eagle's medium supplemented with $10 \%$ fetal calf serum, $100 \mathrm{U} / \mathrm{mL}$ penicillin, $100 \mu \mathrm{g} / \mathrm{mL}$ streptomycin, and $100 \mathrm{mmol} / \mathrm{L}$ pyruvate (PAA, Cölbe, Germany). Cultures were maintained under normoxic conditions in a humidified atmosphere containing $10 \% \mathrm{CO}_{2}$ at $37^{\circ} \mathrm{C}$. On day 13 in vitro, cells were transferred to a 96-well plate at a density of 20,000 cells/well and incubated further for $15 \mathrm{~h}$ with the respective supplements $(1 \mu \mathrm{M}$ losartan, $0.5 \mu \mathrm{g} /$ mL IL-10 antibodies, Biozol, Eching, Germany) with or without glutamate $(1 \mathrm{mmol} / \mathrm{L})$.

Lactate dehydrogenase (LDH) release in the cell culture supernatant was measured by the CytoTox $96{ }^{\circledR}$ NonRadioactive Cytotoxicity Assay (Promega). To determine $\mathrm{LDH}, 50 \mu \mathrm{L}$ of the supernatant of each well was transferred to a separate assay plate, mixed with $50 \mu \mathrm{L}$ substrate mix, and incubated for $30 \mathrm{~min}$ at RT. The enzymatic conversion of a tetrazolium salt into a red formazan product was stopped by $50 \mu \mathrm{L}$ stop solution, and the absorbance was recorded at $490 \mathrm{~nm}$ in a 96-well plate reader (Sunrise, Tecan, 
Crailsheim, Germany). Quantification was done by external standardization with LDH activities in the range between 0 and $800 \mathrm{U} / \mathrm{mL}$ in DMEM (standard supplied in the test kit). The absorbance value of a culture medium control was used to normalize the values obtained from the samples.

\section{Statistical Analyses}

The data presented were analyzed by Student's $t$ test for single comparisons and 1-way ANOVA with Bonferroni test for multiple comparisons. For Kaplan-Meier survival curve analysis, log-rank and Gehan-Breslow-Wilcoxon tests were applied. Results of the neurological scores were analyzed by 2-way ANOVA with the factors "treatment" (between groups) and "time" (within subjects) followed by a post hoc Bonferroni test. The data are presented as means \pm SEM; $p<0.05$ was considered significant.

\section{Results}

\section{Intranasal Losartan Improves Survival and Neurological Scores Without Altering Blood Pressure}

Over $77 \%$ of losartan-treated animals survived until the study end while only $45 \%$ remained alive in the control group (Fig. 1A, cf. PBS vs losartan). Losartan prevented progression of neurological deficits, whereas in the controls neurological scores increased leading to significant differences at every measured point starting from day 24 after treatment onset (Fig. 1B).

Blood pressure constantly increased under $\mathrm{NaCl}$-enriched chow both prior to and during the losartan treatment, and BP settled on a plateau of $221.9 \pm 4.7 \mathrm{mmHg}$ in the final part of the study (Fig. 1C). Neither at the time of group assignment (day 44 after the beginning of $\mathrm{NaCl}$-enriched chow) nor at any tested point during the course of the experiment did the mean systolic BP levels (Fig. 1C) as well as systolic BP 30 min prior to and $24 \mathrm{~h}$ after IN-losartan treatment (Fig. 1D) differ between the groups.

\section{Losartan Reduces Inflammatory Response and $A \beta$ in the Brains of SHRSP}

Among cytokines assessed by multiplex analysis in brain homogenates of SHRSP, IL-1- $\beta$, IL- 6 , and TNF- $\alpha$ decreased with IN-losartan treatment (Fig. 2A-C), while only negligible amounts of IL-4, IL-5, IL-12 p40/p70, GM-CSF, and IFN- $\gamma$ were observed in both losartan and vehicle groups (data not shown). The TNF- $\alpha$-reducing (cf. Fig. 2C) and IL-10increasing effects of losartan (Fig. 2D) were also confirmed by Western blot (cf. Fig. 7A).
$A \beta$ may critically influence cerebral small vessel disease in hemorrhagic stroke, and its parenchymal and vascular accumulation in the brains of SHRSP rats has been reported previously $[20,35]$. Thus, we explored the possible involvement of AT1R and the impact of its blockade on the cerebral content of $A \beta$ in SHRSP. Increased $A \beta 40$ and $A \beta 42$ concentration in vehicle-treated SHRSP was seen in comparison with normotensive Wistar control rats (cf. ctrl. vs PBS in Fig. 2E, F), while losartan reduced the $A \beta$ in the brains of SHRSP down to the level of control rats (Fig. 2E, F). Immunofluorescent assessment of $A \beta 42$ in the cortex of SHRSP and control rats displayed a prominent increase in A $\beta 42$-reactivity of smooth muscle $\alpha$-actin ( $\alpha$-SMA)-positive vessels of vehicle-treated SHRSP in comparison to the controls (cf. Fig. $2 \mathrm{G}$ vs $\mathrm{H}$ ). Similar to the normotensive controls, in the losartan-treated SHRSP, A $\beta 42$ appeared mainly intracellularly within the parenchyma while perivascular immunoreactivity was dramatically decreased in comparison to vehicle-treated SHRSP (cf. Fig. 2H vs I).

\section{AT1R Blockade Induces Cell Proliferation in the Choroid Plexus}

Immunohistochemical staining of brain sections with proliferating cell nuclear antigen (PCNA) and glial fibrillary acidic protein (GFAP, Fig. 3A, B) antibodies showed an increase in $\mathrm{PCNA}+$ /GFAP-negative cells in the choroid plexus $(\mathrm{CP}$, arrow in Fig. 3A) of losartan-treated SHRSP in comparison to vehicle-treated controls (Fig. 3B). PCNA+ cell quantification in the $\mathrm{CP}$ displayed a twofold increase in the losartan-treated group (Fig. 4B).

\section{AT1-R Blockade Enhances Neurogenesis and Attenuates Hippocampal Cell Death}

To address the question whether losartan can increase neurogenesis in SHRSP, we evaluated the expression of neurogenic differentiation factor 1 (NeuroD1), a marker and inducer of neuronal commitment of stem cells [36], and $\beta$ tubulin III, a marker of early neuronal differentiation. Indeed, the expression of NeuroD1 in the subventricular zone (SVZ) was upregulated in losartan-treated animals (cf. Fig. 3c, $\mathrm{d}$, arrowheads). Noteworthy is the appearance of NeuroD1positive cells in the CP with IN-losartan (Fig. 3C, arrow), which are absent in the control group (Fig. 3D). Western Blot analysis demonstrated an increase in NeuroD1 expression in brain homogenates with IN-losartan (Fig. 7A). Also, $\beta$-tubulin III mRNA was increased in the losartan-treated group (Fig. 4C), suggesting better neuronal survival with IN-losartan treatment. This was further verified by the quantification of TUNEL+ cells in the hippocampus. Losartan decreased the area (Fig. 3E, F) and number of TUNEL+ cells (Fig. 4A). The sections counterstained with GFAP (red 
Fig. 1 Effects of intranasal losartan on survival, neurological deficits, and BP in SHRSP. (A) Survival of animals ( $n=9$ per group) from the beginning of drug treatment until the animals were sacrificed. Log-rank $(* * p=$ $0.0093)$ and Gehan-BreslowWilcoxon $(* * p=0.0069)$ tests. The data were normalized to the total amount of animals assigned to the groups prior to losartan administration. (B) Motor and behavioral performance represented in the time course starting from randomization (day 47) until day 83 when the animals were sacrificed. (C) Mean systolic BP before and during losartan treatment. (D) Mean systolic BP within the losartantreated group. Systolic BP was monitored 6 times prior to assignment of animals into the groups (once a week) and 5 times after assignment during the drug treatment period (once a week) $30 \mathrm{~min}$ and $24 \mathrm{~h}$ after losartan administration
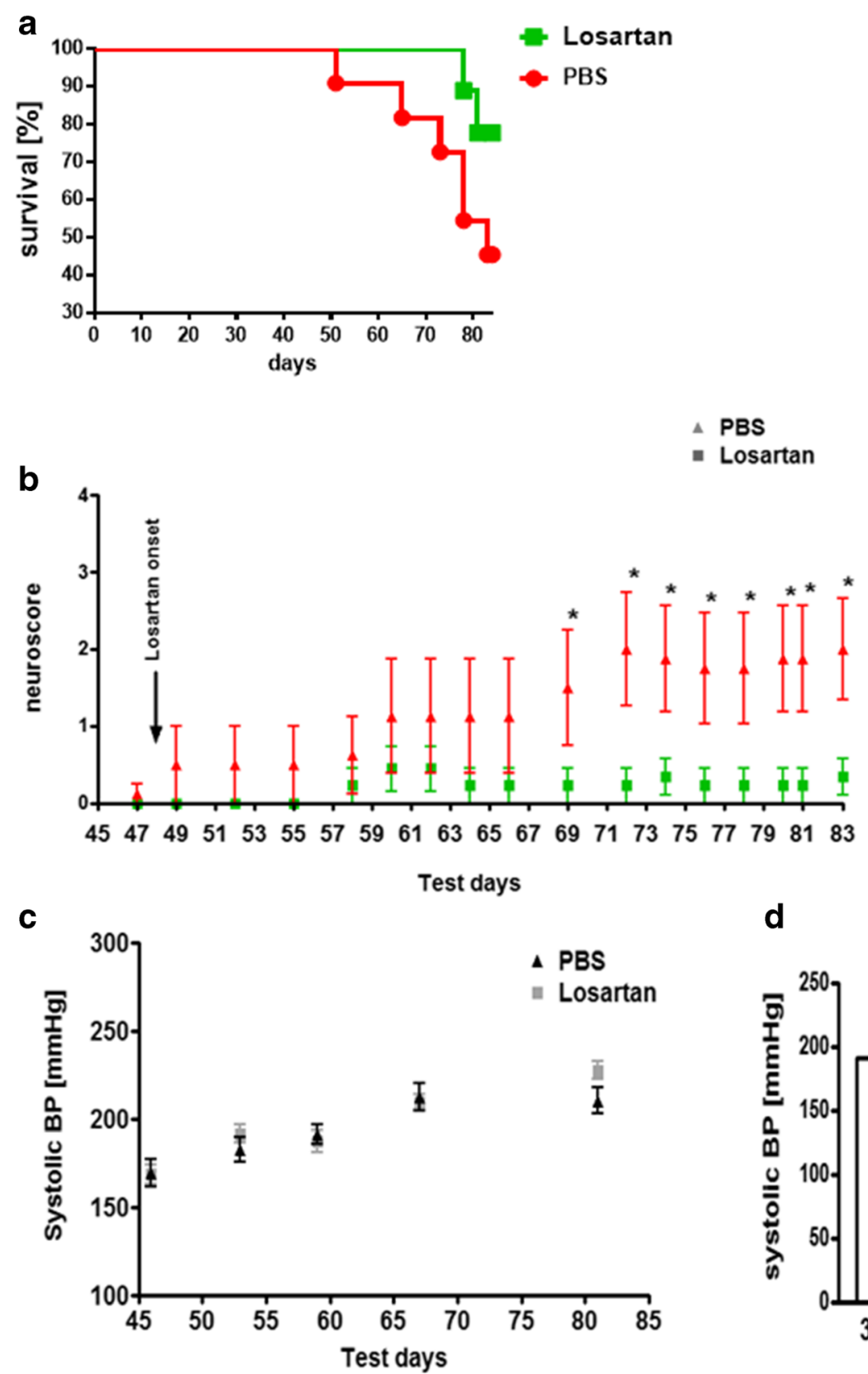

d

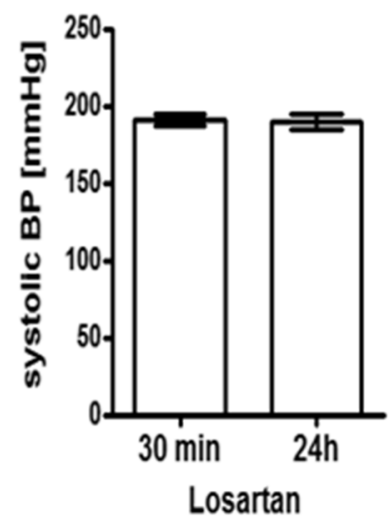

fluorescence in Fig. 3E, F) showed no difference in GFAP intensity in the hippocampi of losartan- and vehicle-treated animals.

\section{A $\beta$ Causes a Direct Effect on Neurogenesis and Vessel Permeability}

To address whether the $A \beta$ increase shown here may be at least partly responsible for reduced neurogenesis in SHRSP, we performed an intraventricular injection (icv) of $\mathrm{A} \beta 42$ in SD rats followed by postmortem analysis of neurogenesis markers. Flow cytometry of hippocampal and SVZ cells displayed a decrease in neurogenesis markers
Sox 2 in the SVZ and nestin and Sox 2 in the hippocampus of $\mathrm{A} \beta$-injected animals (Fig. $5 \mathrm{~A}, \mathrm{~B}$ ). Another critical role of $A \beta$, which may impact the progression of hypertension and $\mathrm{AD}$ brain pathology, is its ability to increase vessel permeability. The direct influence of $A \beta$ on permeability is shown here by an increase of vascular endothelial growth factor (VEGF) in the hippocampus and SVZ (Fig. 5A, B). This finding is in line with the notion that $\mathrm{A} \beta$ deposits in a transgenic AD model are closely associated with an increase in nitric oxide (NO) [37], the potent inducer of endothelial permeability and VEGF [38].

Another common feature of AD pathology and hypertensive stroke is a decrease in choline acetyltransferase (ChAT) 

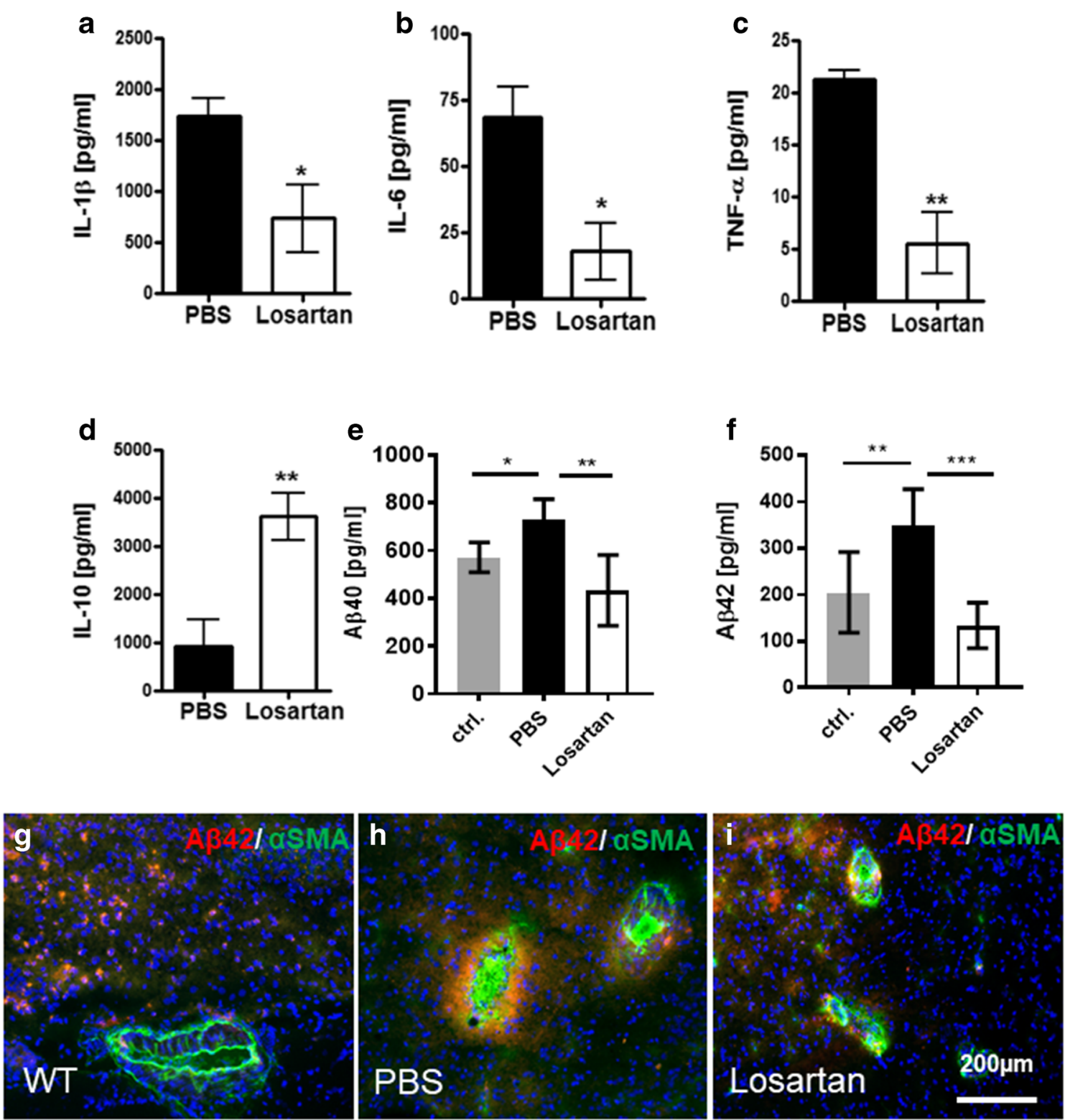

Fig. 2 Losartan effects on inflammatory cytokines and A $\beta$ in SHRSP. Multiplex analysis of the inflammatory cytokines in brain homogenates of SHRSP demonstrates that IN-losartan decreased IL-1 $\beta$ (A), IL-6 (B), and TNF- $\alpha(\mathbf{C})$ while IL-10 was prominently upregulated (D) in comparison to PBS-treated SHRSP controls. (E) and (F) A $\beta 40$ and A $\beta 40$ multiplex analysis in the brain homogenates $(n=5)$ of SHRSP (black and white bars) and age-matched Wistar rats (ctrl., grey bar). (G-I) Immunofluorescent analysis of A $\beta 42$ (red) and vascular smooth muscle cell marker $\alpha$ SMA (green) in the brain sections of SHRSP (PBS and losartan) and age-matched Wistar rats (WT). A 342 is strongly upregulated in vehicle-treated SHRSP $(\mathbf{H})$ in comparison with normotensive controls $(\mathbf{G})$, while losartan diminished the $\mathrm{A} \beta$ load around the vessels in SHRSP (I). 4',6 Diamidino-2-phenylindole (DAPI) counts in blue. The data shown are representative for brain sections obtained from $n=3$ animals per treatment group
[39, 40]. Concomitant with its survival-increasing effects on hippocampal cells, losartan enhanced the expression of ChAT in brain homogenates of SHRSP (Fig. 5C).

To investigate the mechanisms by which losartan influences brain $A \beta$ content in SHRSP, we explored its effects on the main $\mathrm{A} \beta$-metabolizing and transporting proteins: insulin-degrading enzyme (IDE), neprilysin (NEP), and transthyretin (TTR). Western blots (Fig. 5C) and immunofluorescence analyses (Fig. 6A,
B) revealed a prominent increase in the expression of TTR, IDE (Fig. 5C), and neprilysin (Fig. 6A, B) in losartan-treated SHRSP. To clarify which cell type is targeted by losartan to enhance $\mathrm{A} \beta$ clearance, we quantified the NEP-positive astroglia (Fig. 6F) and Ibal+ microglia in the cortex and hippocampus (Fig. 6E). While the number of Iba1+ microglia was reduced (Fig. 6E), astroglia appeared to prominently increase NEP expression following losartan treatment (Fig. 6F). 
Fig. 3 Intranasal losartan increases the population of NeuroD1+ cells and cell proliferation in the choriod plexus and decreases hippocampal cell death in SHRSP. PCNA-positive (red in $\mathbf{A}$ and $\mathbf{B}$ ) cells in the plexus choroideus (arrow) of INlosartan- (A) and vehicle-treated (B) SHRSP. The population of NeuroD1-positive cells (green in $\mathbf{C}$ and $\mathbf{D})$ in the SVZ (arrowheads) and the plexus choroideus (arrow) of losartantreated SHRSP $(\mathbf{C})$ is greater than that of vehicle-treated SHRSP control. (E, F) TUNEL staining (green) in the hippocampus of losartan- (E) and vehicle-treated (F) SHRSP. GFAP (green in A and $\mathbf{B}$ ) expression is demonstrated in green in (A and $\mathbf{B})$ and in red in $(\mathbf{E})$ and $(\mathbf{F})$. Cell nuclei are shown with DAPI (blue in A-F). The data shown are representative for brain sections obtained from $n=3$ rats per treatment group. Scale bars in (D) $(200 \mu \mathrm{m})$ and (F) $(500 \mu \mathrm{m})$ apply to $(\mathbf{A}-\mathbf{D})$ and $(\mathbf{E}-\mathbf{F})$ respectively

\section{Losartan}
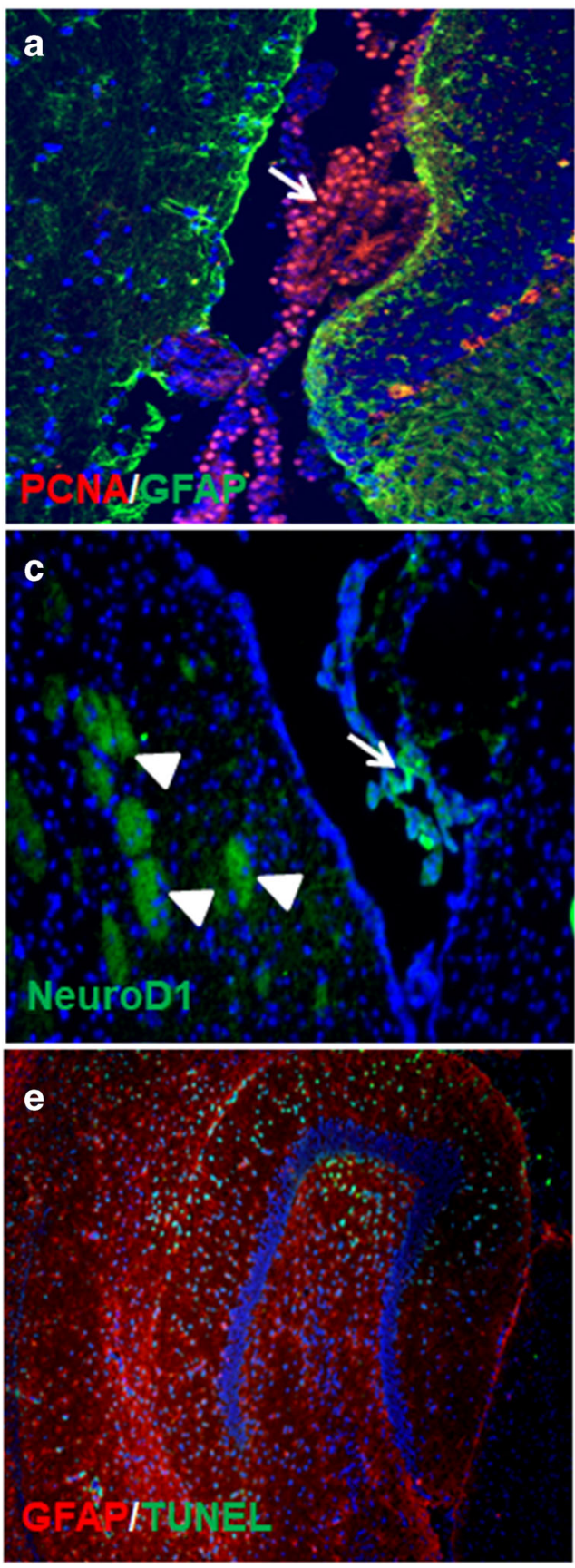

PBS
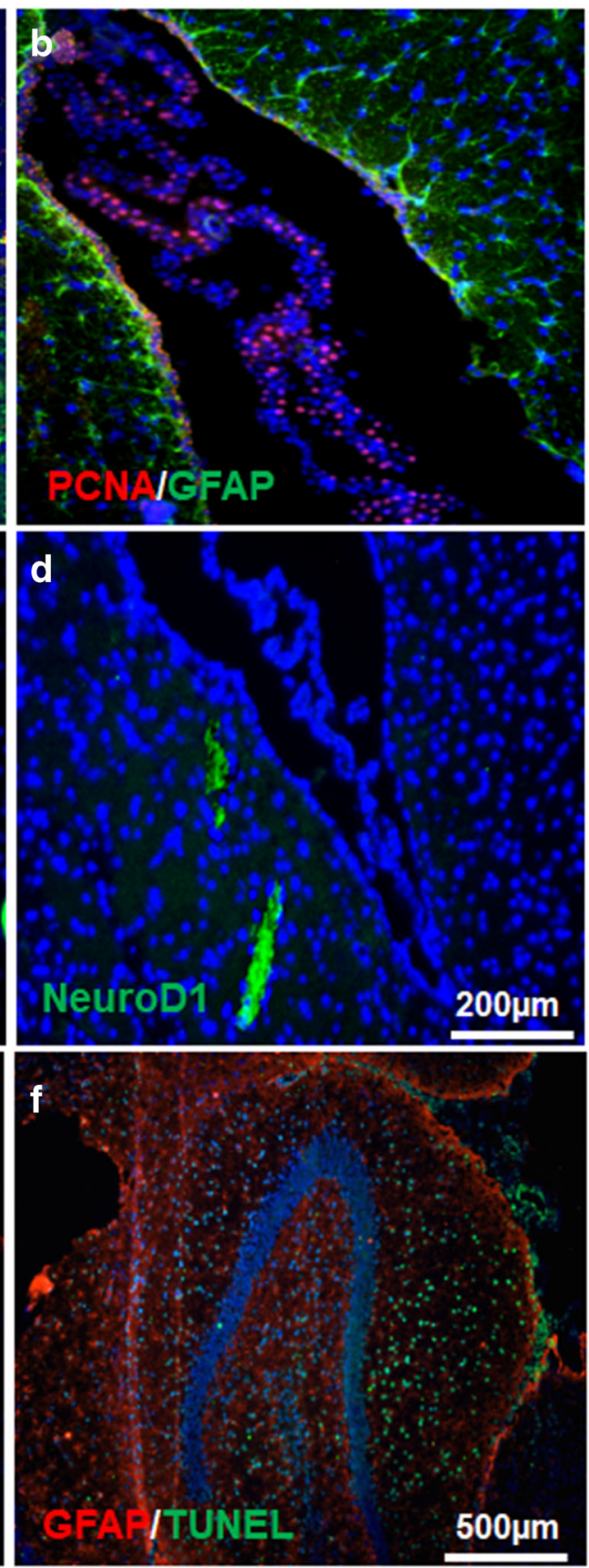

\section{Intranasal Losartan Influences Angiotensin II and AT1- and AT2-Receptor Expression in the Brain Independent of STAT3 Phosphorylation}

Immunoenzymatic measurement of angiotensin II (ATII) in brain homogenates of age-matched Wistar rats and SHRSP demonstrated an increase in ATII in the PBStreated SHRSP (cf. control vs PBS in Fig. 4D). However, the highest concentration of angiotensin II was measured in the losartan-treated SHRSP group (cf. losartan vs PBS in Fig. 4D).

Western blot analysis of AT receptors (AT1R and AT2R) displayed elevated AT2R and decreased AT1R following INlosartan treatment (Fig. 7A).

Keeping in mind the decreased concentration of IL-6 (Fig. 2B) and elevation of ATII (Fig. 4D) in the CNS of losartan-treated SHRSP, we addressed the question of whether or not the phosphorylation of STAT3, which is known to be 


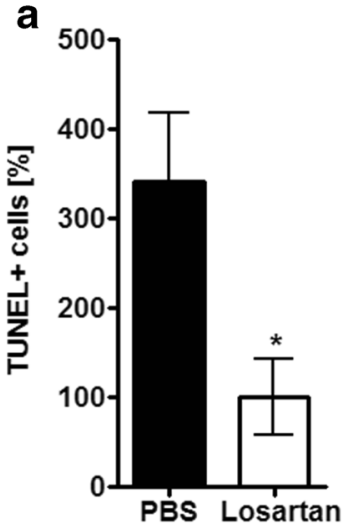

C

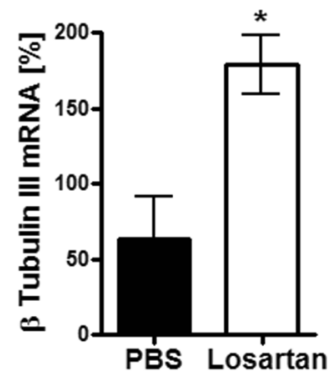

b

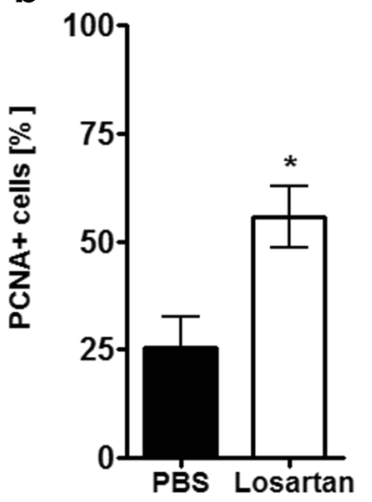

d

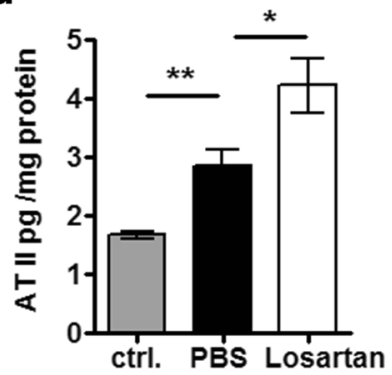

Fig. 4 Losartan effects on cell survival and proliferation and angiotensin II production in the brain of SHRSP. (A) Quantification of TUNEL+ cells in the hippocampus of SHRSP. The data are normalized to the mean of TUNEL+ cell number in the losartan-treated group. (B) Quantification of $\mathrm{PCNA}+$ cells in the choroid plexus demonstrates that IN losartan doubles the number of proliferating cells in comparison to controls. The data are normalized to the total number of cell nuclei counted within the area of choroid plexus. (C) Losartan increases the expression of $\beta$-tubulin III mRNA in the brain homogenates of SHRSP (the mean of PBS-treated control group samples are considered as $100 \%$ ). (D) Measurement of angiotensin II in brain homogenates shows a higher level of angiotensin II in vehicle-treated SHRSP in comparison to normotensive control rats. Losartan induced a further increase in angiotensin in SHRSP

activated by ATII action via involvement of IL-6 [41], would be affected by losartan. Here, we show that the expression of phosphorylated STAT3 remained unchanged in the CNS of SHRSP after IN-losartan treatment (Fig. 7A).

\section{Losartan Increases Survival and Functionality of APC with Exposure to Hypoxia and Glutamate}

Hypoxia and high extracellular content of glutamate (Glu) are 2 common features of AD and hypertensive stroke [42-44]. Whether neuroprotection provided by IN-losartan in glutamate (Glu)-induced cytotoxic conditions can be at least partly ascribed to the increase in IL-10 concentration was addressed by exposure of 14-day-old rat astroglial primary culture (APC) to losartan in the presence of IL-10 antibodies. The vulnerability of cells to Glu was evaluated by LDH release from APC (Fig. 7B). Exposure of APC to $1 \mathrm{mmol} / \mathrm{L} \mathrm{Glu}$ increased the LDH release (cf. - Glu and + Glu in Fig. 7B), while administration of $1 \mu \mathrm{mol} / \mathrm{L}$ losartan significantly

reduced the LDH in the cell culture supernatant (cf. +Glu with Glu+Los in Fig. 7B). IL-10 antibodies not only completely abolished the effect of losartan on APC but also dramatically increased the vulnerability of cells to Glu, reflected by the increase in LDH in comparison with Glu-treated controls (cf. +Glu with Glu+Los+IL-10Ab in Fig. 7B). To clarify glial cell engagement in in vivo effects of IN-losartan, we assessed the markers of neurogenesis, - cholinergic activity, and $\mathrm{A} \beta$ clearance in APC following normoxia and hypoxia. Exposure of APC to hypoxia led to the more pronounced losartaninduced increase in expression of NeuroD1, IL-10 (Fig. 7C and Fig. 8A), postsynaptic density marker PSD95, NEP, and ChAT in APC (Fig. 8B, D). Taken together, the in vitro results confirmed improvement of neurogenesis, synaptic, cholinergic, and A $\beta$-metabolizing activity by losartan in APC suggesting that enhanced functionality and survival of astrocytes are likely to contribute to the in vivo neuroprotection provided by losartan.

\section{Discussion}

Here, we demonstrate the BP-independent protective action of intranasal ARB in a hemorrhagic model of stroke. A striking decrease in mortality of SHRSP has never been described previously for ARBs or any other anti-hypertensive drug applied intranasally. In contrast to our current study, a previous investigation applying intranasal vaccine against AT1R was aimed primarily at testing its BP-lowering effect [45]. INlosartan improved the neurologic deficits in SHRSP leaving the high systolic blood pressure unaffected. Our data contribute to the establishment of a new therapeutically efficacious intranasal delivery of subdepressor dose of ARB to the CNS to decrease the mortality, neuroinflammation, and vulnerability of neural cells to hypoxia and to improve the neurological scores, neurogenesis, and $\mathrm{A} \beta$ clearance in hemorrhagic stroke and CAA.

Inflammation, reflected by elevated cytokines such as IL1- $\beta$ [3], IL-6, and TNF- $\alpha$ [46], occurs in SHRSP and aggravates the outcome after ischemic stroke [47]. Suppressed intracerebral levels of these cytokines with IN-losartan treatment are consistent with previous reports on antiinflammatory effects of ARBs in traumatic brain injury [16], Alzheimer's [4], Parkinson's disease [5], multiple sclerosis [17], and hemorrhagic stroke [3] models. Our results support the benefit of low-dose IN-losartan in inflammationassociated diseases, which will avoid systemic effects of ARBs. Here, we show a losartan-induced increase in the intracerebral level of IL-10 in brain homogenates of SHRSP by a factor of almost 4 . This finding is in line with previous reports of IL-10-increasing effects of low-dose ARBs in the brain of the hypertensive rat model of renal artery occlusion [7] and in the blood serum of transgenic AD mice [4]. Our 
Fig. 5 A $\beta 42$ influence on neurogenesis markers and VEGF in vivo and losartan's effect on A $\beta$-degrading enzymes and ChAT in SHRSP. (A, B) Flow cytometry of hippocampal and SVZ cells after bilateral injection of fibrillar A $\beta 42$ into the lateral ventricle of SD rats $(n=5)$. $\mathrm{A} \beta 42$ decreased the expression of nestin in the subventricular zone (SVZ) and Sox 2 in the SVZ and hippocampus. A prominent upregulation of VEGF was seen in the SVZ and hippocampus of A 342 -treated rats. (C) Western blot of TTR, IDE, and ChAT in the brain homogenates of SHRSP showing losartan-induced increase of all 3 marker proteins. GAPDH serves as a loading control

SD Rats with $A \beta$ injection

a

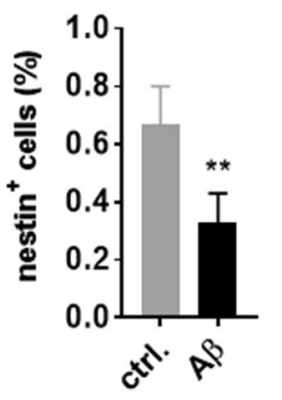

b

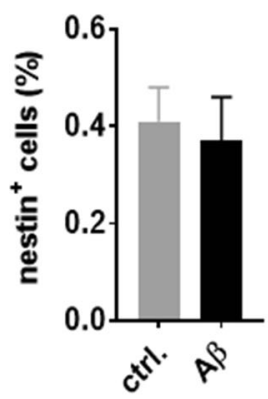

SVZ

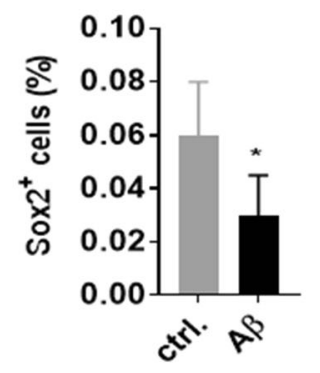

Hippocampus
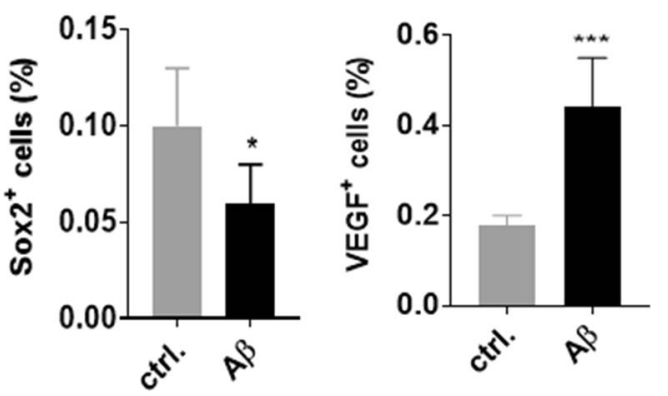

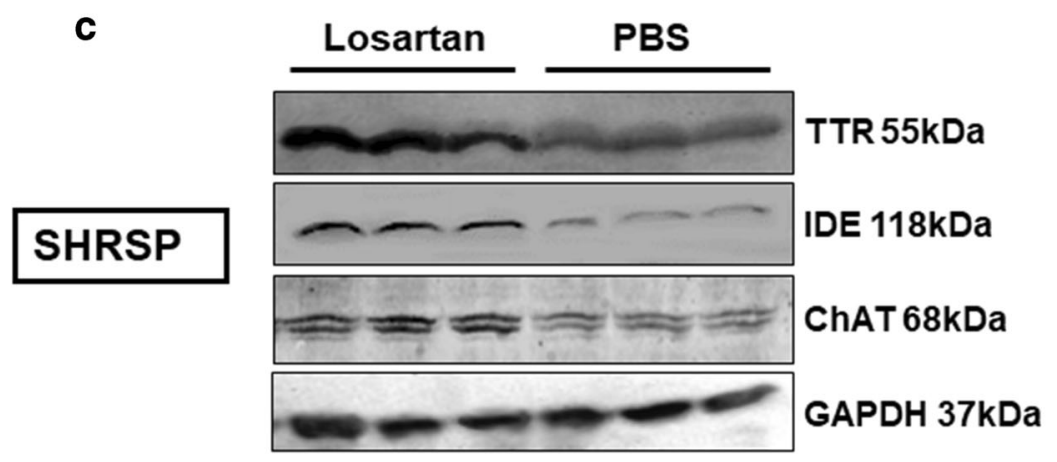

in vitro data show that losartan protects astroglia from toxic concentrations of Glu. Since this protection is completely abrogated by IL-10 antibodies, the in vivo neuroprotection provided by losartan can be at least partly explained by its effect on neural cells to induce IL-10. IL-10 represents a promising target for reducing SHRSP pathologies by neuroprotection [48]. However, upregulated IL-10 in losartan-treated SHRSP is shown here to act independently from STAT3 signaling, which has been previously reported to be an important player in the neuroprotective features of IL-10 [48] and ARB [49].

Cerebral amyloid angiopathy (CAA) coexists with hypertension in patients with intracerebral hemorrhage [19] and in SHRSP [20, 50]. The capacity of IN-losartan to decrease
$A \beta 40$ and $A \beta 42$ in SHRSP involves a variety of its effects shown here. Neuronal A $\beta$ toxicity [51] can contribute to hippocampal cell loss in SHRSP reflected by TUNEL positivity that is blunted by losartan. Previous evidence of in vitro $\mathrm{A} \beta 42$ influence on VEGF demonstrating an increase of VEGF-A secretion in astroglia [52] or unchanged VEGF in human transformed endothelial cell line [53] has been addressed in our study by in vivo icv injection of $\mathrm{A} \beta 42$ in SD rats. Here, we show that $A \beta 42$ is capable of increasing the overall production of VEGF in the SVZ and hippocampus. Intracerebroventricular injection of $\mathrm{A} \beta 42$ also led to a decrease in neurogenesis markers (Sox2, nestin) and VEGF, while IN-losartan enhanced neurogenesis in the SVZ and CP 
Fig. 6 Losartan enhances NEP+ cells and decreases Iba+ microglia/macrophages in the cortex and hippocampus of SHRSP. (A) Weak expression of NEP (red) in GFAP (green)negative neurons in the cortex of PBS-treated SHRSP. (B)

Prominent increase in expression intensity and in number of NEP+ cells in losartan-treated SHRSP in both GFAP+ astroglia and GFAPnegative neurons. (C) High number of Iba1+ microglia/ macrophages in the vehicletreated SHRSP in the cortex. (D) Decrease in Iba1+ microglia/ macrophages in the cortex of losartan-treated SHRSP, while GFAP+ astroglia (red in C and D) remained unaffected. DAPI+ cell nuclei are shown in blue. (E) Quantification of Iba-1+ cells in the cortex and hippocampus of vehicle- (black bars) and losartantreated (white bars) SHRSP ( $n=3$ per group). (F) Number of NEP+ cells in the cortex and

hippocampus of SHRSP. The data in $(\mathbf{E})$ and $(\mathbf{F})$ were obtained from 10 brain sections/animal $(n=3$ animals per treatment group) and normalized to square millimeters. Scale bar in (A, B) $100 \mu \mathrm{m}$, in $(\mathbf{C}$, D) $200 \mu \mathrm{m}$
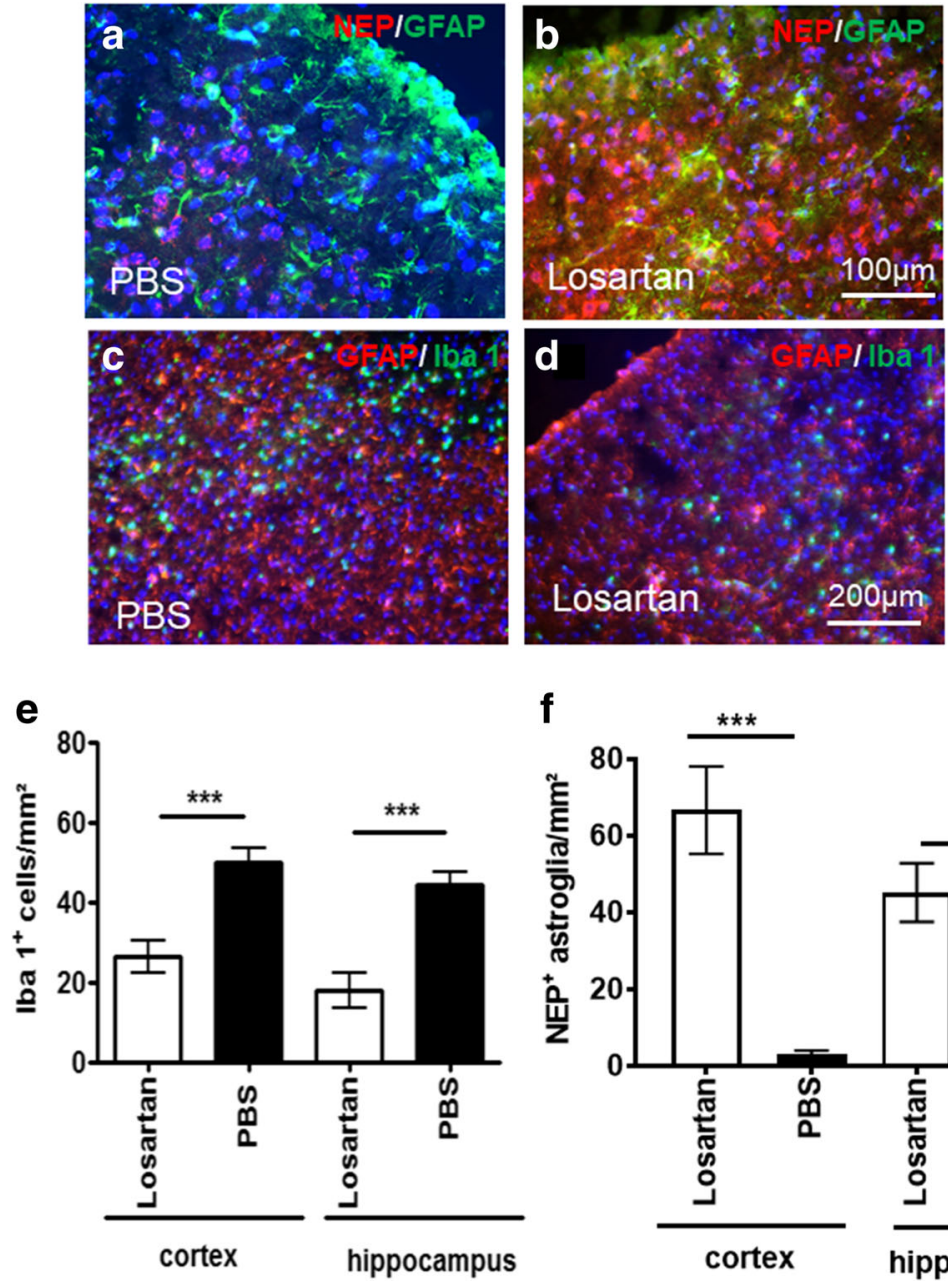

f

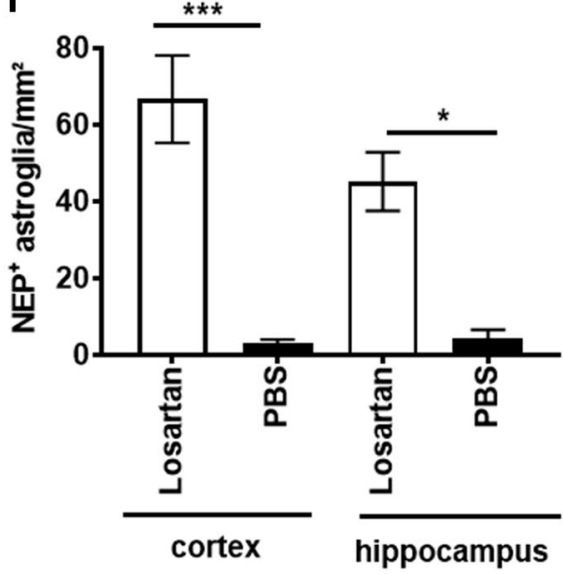

in SHRSP. Whether A $\beta 42$ decreases or induces neurogenesis in the hippocampus is a topic of controversy raised in several studies. Russo et al. [54] reported an increased proliferation of hippocampal progenitor cells in response to icv injection of A $\beta 42$, while Kimura et al. [55] showed a decrease in hippocampal neurogenesis after icv injection of $A \beta 42$. However, none of the previous studies assessed or reported the decline of neurogenesis in the subventricular zone caused by $A \beta 42$ which is shown here.

The VEGF-increasing effect of $A \beta$ can be further enhanced by ARBs which are potent inducers of VEGF [56]. In this context, the dual role of VEGF is noteworthy. On one hand, VEGF increases vessel permeability and thus may impair the blood-brain barrier function, and on the other hand, VEGF is a well-known neuroprotective and endothelial functionregulating factor. Despite its dual role, VEGF is considered a therapeutically potent agent to treat CAA and small vessel disease in $\mathrm{AD}$, since it is part of the physiological defensive response of brain tissue to hypoxia and hypoperfusion [57]. In addition, the direct delivery of candesartan into the brain via osmotic pumps has been shown to reverse the pathological vascular hypertrophy, to increase endothelial nitric oxide synthase expression (an inductor of VEGF), and to decrease the number of adherent and infiltrating macrophages in cerebral vessels of SHRSP [58]. Similar to candesartan, losartan may decrease the number of macrophages invading the brain parenchyma from the vessels reflected by our data showing a decrease in Iba- $1+$ cells in the cortex and hippocampus of the losartan-treated animals.

Losartan decreases $A \beta 40$ and $A \beta 42$ most likely by increasing the proteins involved in its metabolism (NEP, IDE, and TTR) and clearance (TTR, [59]) from the brain. The facilitated $A \beta$ clearance in losartan-treated SHRSP is further supported by increased proliferation of CP cells, which are the major intracerebral producers of TTR. Noteworthy in this context is a decrease in TTR in AD-like transgenic mice [60] and the fact that a low blood level of TTR is predictive of a poor outcome in stroke patients [61].

Our in vitro results support the in vivo effects of losartan in SHRSP. When exposed to glutamate and hypoxia, both of which are the components of cerebral ischemia and AD-like pathology [42-44], losartan increased ChAT, NEP, and IL-10 in astroglia exposed to hypoxia and enhanced the survival of astrocytes following exposure to glutamate, which was IL-10 


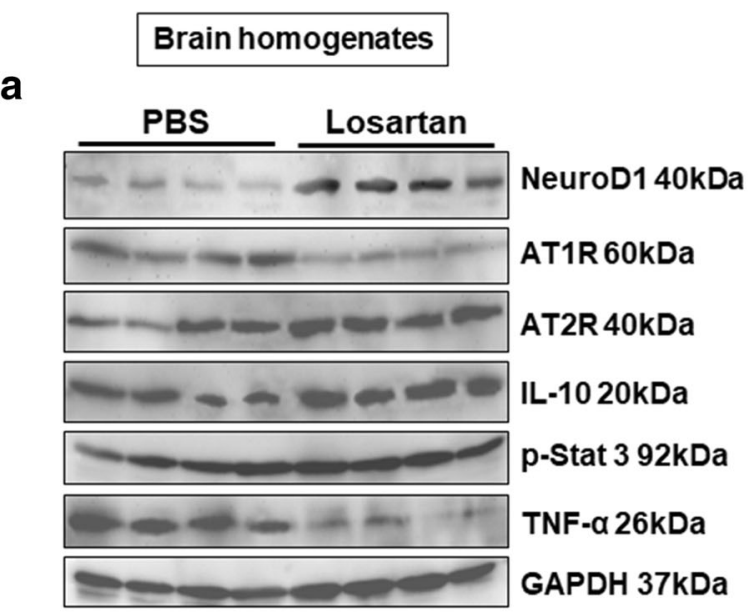

Brain primary culture

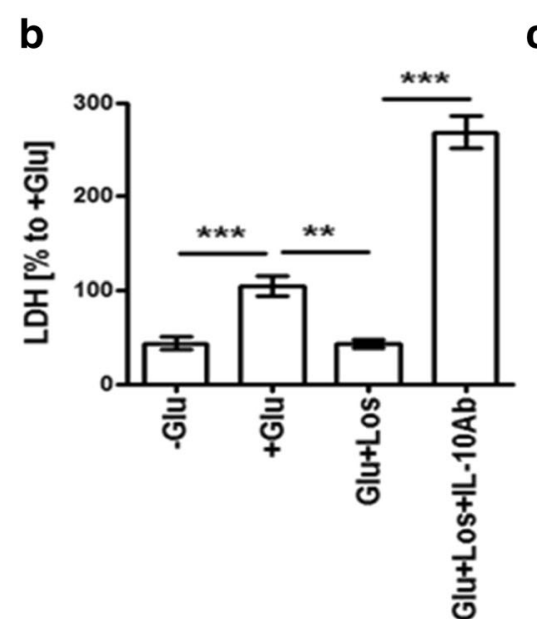

Fig. 7 Influence of IN-losartan on angiotensin receptors (ATR) 1 and 2, phosphorylated STAT3, IL-10, NeuroD1, TNF- $\alpha$, and Abeta1-40 in SHRSP and on the survival of astroglia in vitro. (A) Western blot of AT1R and AT2R, phosphorylated STAT3, NeuroD1, IL-10, and TNF- $\alpha$ in the brain homogenates of losartan- and vehicle-treated SHRSP. GAPDH serves as a loading control. (B) Astroglial primary culture (day 14 in vitro) incubated with $1 \mathrm{mmol} / \mathrm{L}$ Glu (+Glu in B) showed a prominent increase in $\mathrm{LDH}$ release in comparison to the control without Glu (cf. -Glu with +Glu), whereas IN-losartan decreased LDH down to the level of the Glu-free control (cf. Glu+Los with +Glu and -Glu).

dependent. Enhanced astroglial PSD95 suggests improvement of synaptic activity by losartan which is in line with a previous report showing increased PSD95 expression in low-dose candesartan-treated rats having the middle cerebral artery occlusion as a model of stroke [56]. Our data along with previous reports suggest that at least some neuroprotective features are common for low-dose ARBs. The present study shows that intranasal $0.24 \mathrm{mg}$ losartan effectively provides remarkable protection to the brain alleviating neurologic deficits and increasing the survival of SHRSP rats. These findings are in line with previously shown therapeutic effects of different
C - - + + Hypoxia

- + - + Losartan
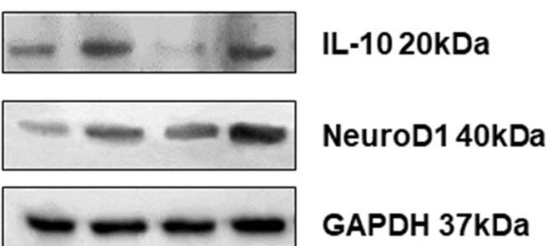

Losartan-treated cells exposed simultaneously to IL-10 antibodies, losartan, and Glu (Glu+Los+IL-10Ab) showed a dramatic increase in LDH release over the control culture exposed to Glu only (cf. +Glu with Glu+Los+IL-10Ab). The data are normalized to the control exposed to Glu (+Glu). (C) Western blot of IL-10 and NeuroD1 from untreated and losartan-treated astroglial primary culture in 48-h normoxic and hypoxic conditions. Cell lysates from $n=5$ different culture dishes were pooled prior to the Western blot analysis. GAPDH serves as a loading control

ARBs in a 5XFAD model of AD, where the given doses of candesartan or telmisartan were lower than the equipotent losartan dose used in our study $[62,63]$. Whether the neuroprotective features of intranasal ARBs are concentrationdependent and whether the delivery efficacy after intranasal administration varies between different ARBs remain to be investigated.

In summary, our study suggests that AT1 blockade in the CNS via low-dose IN-losartan results in anti-inflammatory, anti-apoptotic, cytoprotective, A $\beta$-degrading, and neurogenesis-inducing effects in a rat model of hemorrhagic 
Fig. 8 In vitro effects of losartan on rat astroglial primary culture. Losartan increased the expression of IL-10 (A), PSD95 (B),

Neprilysin (NEP) (C), and ChAT mRNA (D) in APC upon hypoxic culture conditions. qPCR analysis of IL-10, PSD95, Neprilysin, and ChAT in astroglial primary culture (APC) under normoxic (white bars) and hypoxic culture conditions (grey bars)

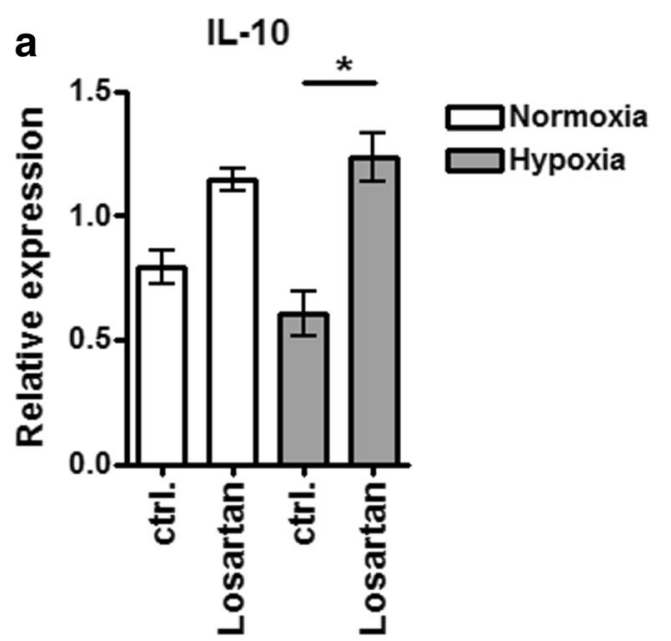

b PSD95

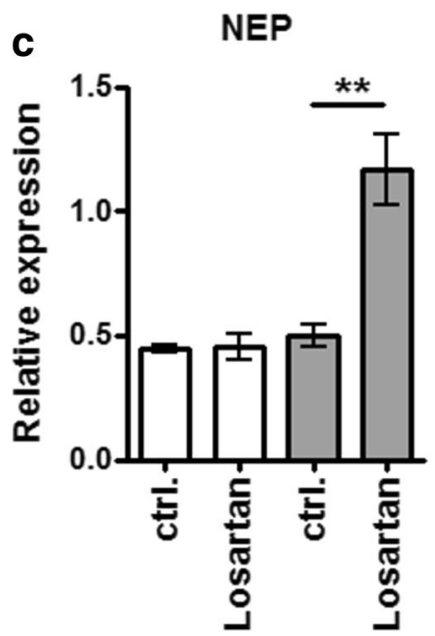

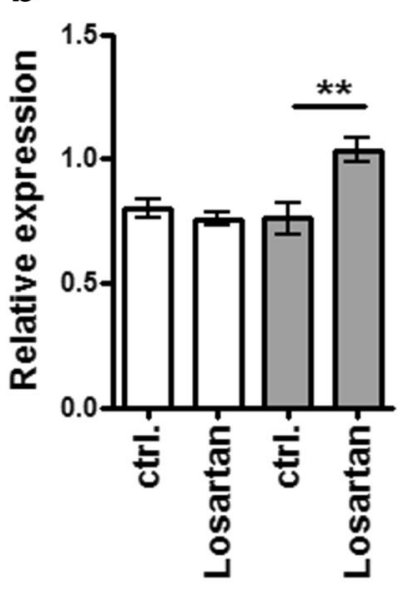

d

ChAT

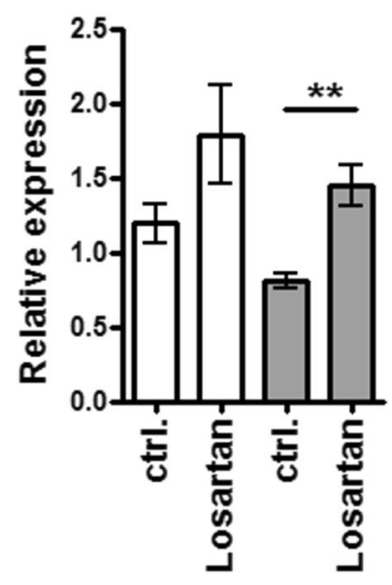

stroke. Some of these effects can be at least partly ascribed to the STAT3-independent IL-10 pathway and the capacity of losartan to lower the perivascular and intraparenchymal content of $A \beta$. Thus, intranasal lowdose ARBs should be considered and further investigated for the treatment of cerebrovascular disorders associated with inflammation, neuronal loss, decreased neurogenesis, and $\mathrm{A} \beta$ pathology as a direct treatment regime, targeting the CNS without exerting systemic effects.

Acknowledgments We wish to thank Claudia Müller, Barbara Proksch, and Michael Glaser for excellent technical assistance.

Funding Sources This study was supported by the Dr. Karl-Kuhn Foundation and Interfaculty Centre for Pharmacogenomics and Pharma Research (Grant number 15-0-0), Germany, given to L.D. M.S. was supported in part by the Robert Bosch Stiftung, Stuttgart, Germany.

\section{Compliance with Ethical Standards}

Conflict of Interest The authors declare that they have no conflict of interest.
Required Author Forms Disclosure forms provided by the authors are available with the online version of this article.

Publisher's Note Springer Nature remains neutral with regard to jurisdictional claims in published maps and institutional affiliations.

\section{References}

1. Daulatzai MA. Cerebral hypoperfusion and glucose hypometabolism: key pathophysiological modulators promote neurodegeneration, cognitive impairment, and Alzheimer's disease. J Neurosci Res 2017;95:943-72.

2. Kalaria RN, Ballard C. Overlap between pathology of Alzheimer disease and vascular dementia. Alzheimer Dis Assoc Disord 1999;13:S115-23.

3. Sironi L, Gelosa P, Guerrini U, et al. Anti-inflammatory effects of AT1 receptor blockade provide end-organ protection in strokeprone rats independently from blood pressure fall. J Pharmacol Exp Ther 2004;311:989-95.

4. Danielyan L, Klein R, Hanson LR, Buadze M, Schwab M, Gleiter $\mathrm{CH}$, et al. Protective effects of intranasal losartan in the APP/PS1 transgenic mouse model of Alzheimer disease. Rejuvenation Res 2010;13:195-201. 
5. Joglar B, Rodriguez-Pallares J, Rodriguez-Perez AI, Rey P, Guerra MJ, Labandeira-Garcia JL. The inflammatory response in the MPTP model of Parkinson's disease is mediated by brain angiotensin: relevance to progression of the disease. J Neurochem 2009;109: 656-69.

6. Fournier A, Oprisiu-Fournier R, Serot JM, Godefroy O, Achard JM, Faure S, et al. Prevention of dementia by antihypertensive drugs: how AT1-receptor-blockers and dihydropyridines better prevent dementia in hypertensive patients than thiazides and ACEinhibitors. Expert Rev Neurother 2009;9:1413-31.

7. Bhat SA, Goel R, Shukla S, Shukla R, Hanif K. Angiotensin receptor blockade by inhibiting glial activation promotes hippocampal neurogenesis via activation of $\mathrm{Wnt} / \beta$-catenin signaling in hypertension. Mol Neurobiol 2018;55:5282-98.

8. Balin BJ, Broadwell RD, Salcman M, El-Kalliny M. Avenues for entry of peripherally administered protein to the central nervous system in mouse, rat, and squirrel monkey. J Comp Neurol 1986;251:260-80.

9. Dhuria S V., Hanson LR, Frey WH. Intranasal delivery to the central nervous system: mechanisms and experimental considerations. J Pharm Sci 2010;99:1654-73.

10. Thorne RG, Pronk GJ, Padmanabhan V, Frey WH. Delivery of insulin-like growth factor-I to the rat brain and spinal cord along olfactory and trigeminal pathways following intranasal administration. Neuroscience 2004;127:481-96.

11. Frey WH, Liu J, Chen X, Thorne RG, Fawcett JR, Ala TA, et al. Delivery of125I-NGF to the brain via the olfactory route. Drug Deliv 1997;4:87-92.

12. Hadaczek P, Yamashita Y, Mirek H, Tamas L, Bohn MC, Noble C, et al. The "perivascular pump" driven by arterial pulsation is a powerful mechanism for the distribution of therapeutic molecules within the brain. Mol Ther 2006;14:69-78.

13. Danielyan L, Schafer R, von Ameln-Mayerhofer A, Buadze M, Geisler J, Klopfer T, et al. Intranasal delivery of cells to the brain. Eur J Cell Biol 2009.

14. Schiöth HB, Craft S, Brooks SJ, Frey WH, Benedict C. Brain insulin signaling and Alzheimer's disease: current evidence and future directions. Mol Neurobiol 2012;46:4-10.

15. Faraci FM. Protecting against vascular disease in brain. Am J Physiol Heart Circ Physiol 2011.

16. Knoblach SM, Faden AI. Interleukin-10 improves outcome and alters proinflammatory cytokine expression after experimental traumatic brain injury. Exp Neurol 1998;153:143-51.

17. Platten M, Youssef S, Hur EM, Ho PP, Han MH, Lanz T V., et al. Blocking angiotensin-converting enzyme induces potent regulatory $\mathrm{T}$ cells and modulates TH1- and TH17-mediated autoimmunity. Proc Natl Acad Sci 2009;106:14948-53.

18. Torika N, Asraf K, Cohen H, Fleisher-Berkovich S. Intranasal telmisartan ameliorates brain pathology in five familial Alzheimer's disease mice. Brain Behav Immun 2017;64:80-90.

19. Guidoux C, Hauw JJ, Klein IF, Labreuche J, Berr C, Duyckaerts C, et al. Amyloid angiopathy in brain hemorrhage: a postmortem neuropathological-magnetic resonance imaging study. Cerebrovasc Dis 2018;45:124-31.

20. Bueche CZ, Hawkes C, Garz C, Vielhaber S, Attems J, Knight RT, et al. Hypertension drives parenchymal $\beta$-amyloid accumulation in the brain parenchyma. Ann Clin Transl Neurol 2014;1:124-9.

21. Takeda S, Sato N, Takeuchi D, Kurinami H, Shinohara M, Niisato $\mathrm{K}$, et al. Angiotensin receptor blocker prevented $\beta$-amyloidinduced cognitive impairment associated with recovery of neurovascular coupling. Hypertension 2009;54:1345-52.

22. Kimura Y, Kitagawa K, Oku N, Kajimoto K, Kato H, Tanaka M, et al. Blood pressure lowering with valsartan is associated with maintenance of cerebral blood flow and cerebral perfusion reserve in hypertensive patients with cerebral small vessel disease. J Stroke Cerebrovasc Dis 2010;19:85-91.
23. Bennai F, Morsing P, Paliege A, Ketteler M, Mayer B, Tapp R, et al. Normalizing the expression of nitric oxide synthase by low-dose AT1 receptor antagonism parallels improved vascular morphology in hypertensive rats. J Am Soc Nephrol 1999;10 Suppl 1:S104-15.

24. Staudacher T, Pech B, Tappe M, Gross G, Mühlbauer B, Luippold G. Arterial blood pressure and renal sodium excretion in dopamine D3 receptor knockout mice. Hypertens Res 2007;30:93-101.

25. Yamori Y, Horie R, Akiguchi I, Kihara M, Nara Y, Lovenberg W. Symptomatological classification in the development of stroke in stroke-prone spontaneously hypertensive rats. Jpn Circ J 1982;46: 274-83.

26. Albert FW, Shchepina O, Winter C, Römpler H, Teupser D, Palme $\mathrm{R}$, et al. Phenotypic differences in behavior, physiology and neurochemistry between rats selected for tameness and for defensive aggression towards humans. Horm Behav 2008.

27. Boltze J, Kowalski I, Förschler A, Schmidt U, Wagner D, Lobsien $\mathrm{D}$, et al. The stairway: a novel behavioral test detecting sensomotoric stroke deficits in rats. Artif Organs, vol. 30, 2006, p. 756-63.

28. Lenhard SC, Strittmatter R, Price WJ, Chandra S, White RF, Barone FC. Brain MRI and neurological deficit measurements in focal stroke: rapid throughput validated with isradipine. Pharmacology 2007;81:1-10.

29. Tominaga T, Ohnishi ST. Interrelationship of brain edema, motor deficits, and memory impairment in rats exposed to focal ischemia. Stroke 1989;20:513-8.

30. Bederson JB, Pitts LH, Tsuji M, Nishimura MC, Davis RL, Bartkowski H. Rat middle cerebral artery occlusion: evaluation of the model and development of a neurologic examination. Stroke 1986;17:472-6.

31. Garcia JH, Wagner S, Liu K-F, Hu X-J. Neurological deficit and extent of neuronal necrosis attributable to middle cerebral artery occlusion in rats: statistical validation. Stroke 1995;26:627-35.

32. Maguire S, Strittmatter R, Chandra S, Barone FC. Stroke-prone rats exhibit prolonged behavioral deficits without increased brain injury: an indication of disrupted post-stroke brain recovery of function. Neurosci Lett 2004;354:229-33.

33. Hunter AJ, Hatcher J, Virley D, Nelson P, Irving E, Hadingham SJ, et al. Functional assessments in mice and rats after focal stroke. Neuropharmacology 2000;39:806-16.

34. Paxinos G WC. The rat brain in stereotaxic coordinates. San Diego: Academic Press 1998:400.

35. Held F, Morris AWJ, Pirici D, Niklass S, Sharp MMG, Garz C, et al. Vascular basement membrane alterations and $\beta$-amyloid accumulations in an animal model of cerebral small vessel disease. Clin Sci 2017;131:1001-13.

36. Roybon L, Deierborg T, Brundin P, Li JY. Involvement of Ngn2, Tbr and NeuroD proteins during postnatal olfactory bulb neurogenesis. Eur J Neurosci 2009;29:232-43.

37. Chakroborty S, Kim J, Schneider C, West AR, Stutzmann GE. Nitric oxide signaling is recruited as a compensatory mechanism for sustaining synaptic plasticity in Alzheimer's disease mice. J Neurosci 2015;35:6893-902.

38. Dulak J, Józkowicz A, Dembinska-Kiec A, Guevara I, Zdzienicka A, Zmudzinska-Grochot $\mathrm{D}$, et al. Nitric oxide induces the synthesis of vascular endothelial growth factor by rat vascular smooth muscle cells. Arterioscler Thromb Vasc Biol 2000;20:659-66.

39. Yamada S, Ishima T, Hayashi M, Tomita T, Hayashi E. Muscarinic cholinoceptors and choline acetyltransferase activity in the hypothalamus of spontaneously hypertensive rats. Life Sci 1984;34: 2151-8.

40. Sharp SI, Francis PT, Elliott MSJ, Kalaria RN, Bajic N, Hortobagyi $\mathrm{T}$, et al. Choline acetyltransferase activity in vascular dementia and stroke. Dement Geriatr Cogn Disord 2009;28:233-8.

41. Brands MW, Banes-Berceli AKL, Inscho EW, Al-Azawi H, Allen AJ, Labazi H. Interleukin 6 knockout prevents angiotensin II 
hypertension: role of renal vasoconstriction and janus kinase 2/ signal transducer and activator of transcription 3 activation. Hypertension 2010;56:879-84.

42. Tilleux S, Hermans E. Neuroinflammation and regulation of glial glutamate uptake in neurological disorders. J Neurosci Res 2007;85:2059-70.

43. Ogunshola OO, Antoniou X. Contribution of hypoxia to Alzheimer's disease: is HIF- $1 \alpha$ a mediator of neurodegeneration? Cell Mol Life Sci 2009;66:3555-63.

44. Gemba T, Matsunaga K, Ueda M. Changes in extracellular concentration of amino acids in the hippocampus during cerebral ischemia in stroke-prone SHR, stroke-resistant SHR and normotensive rats. Neurosci Lett 1992;135:184-8.

45. Azegami T, Yuki Y, Hayashi K, Hishikawa A, Sawada SI, Ishige K, et al. Intranasal vaccination against angiotensin II type 1 receptor and pneumococcal surface protein A attenuates hypertension and pneumococcal infection in rodents. J Hypertens 2018;36:387-94.

46. Yamamoto E, Tamamaki N, Nakamura T, Kataoka K, Tokutomi Y, Dong YF, et al. Excess salt causes cerebral neuronal apoptosis and inflammation in stroke-prone hypertensive rats through angiotensin II-induced NADPH oxidase activation. Stroke 2008;39:3049-56.

47. McCabe C, Gallagher L, Gsell W, Graham D, Dominiczak AF, MacRae IM. Differences in the evolution of the ischemic penumbra in stroke-prone spontaneously hypertensive and Wistar-Kyoto rats. Stroke 2009;40:3864-8.

48. Sharma S, Yang B, Xi X, Grotta JC, Aronowski J, Savitz SI. IL-10 directly protects cortical neurons by activating PI-3 kinase and STAT-3 pathways. Brain Res 2011;1373:189-94.

49. Miyamoto N, Zhang N, Tanaka R, Liu M, Hattori N, Urabe T. Neuroprotective role of angiotensin II type 2 receptor after transient focal ischemia in mice brain. Neurosci Res 2008;61:249-56.

50. Schreiber S, Drukarch B, Garz C, Niklass S, Stanaszek L, Kropf S, et al. Interplay between age, cerebral small vessel disease, parenchymal amyloid- $\beta$, and tau pathology: Longitudinal studies in hypertensive stroke-prone rats. J Alzheimers Dis, vol. 42, 2014, p. S205-15.

51. Kwakowsky A, Potapov K, Kim S, Peppercorn K, Tate WP, Ábrahám IM. Treatment of beta amyloid 1-42 (A $\beta 1-42)$-induced basal forebrain cholinergic damage by a non-classical estrogen signaling activator in vivo. Sci Rep 2016;6.

52. Chiarini A, Whitfield J, Bonafini C, Chakravarthy B, Armato U, Dal Prà I. Amyloid- $\beta 25-35$, an amyloid- $\beta 1-42$ surrogate, and proinflammatory cytokines stimulate VEGF-A secretion by cultured, early passage, normoxic adult human cerebral astrocytes. J Alzheimers Dis 2010;21:915-26.

53. Park SY, Chae CB. Toxic levels of amyloid beta peptide do not induce VEGF synthesis. Mol Cell 2007;24:69-75.

54. Russo I, Caracciolo L, Tweedie D, Choi SH, Greig NH, Barlati S, et al. 3,6'-Dithiothalidomide, a new TNF- $\alpha$ synthesis inhibitor, attenuates the effect of A $\beta 1$-42intracerebroventricular injection on hippocampal neurogenesis and memory deficit. J Neurochem 2012;122:1181-92.

55. Kimura T, Nguyen PTH, Ho SA, Tran AH, Ono T, Nishijo H. T-817MA, a neurotrophic agent, ameliorates the deficits in adult neurogenesis and spatial memory in rats infused i.c.v. with amyloid- $\beta$ peptide. Br J Pharmacol 2009;157:451-63.

56. Ishrat T, Pillai B, Soliman S, Fouda AY, Kozak A, Johnson MH, et al. Low-dose candesartan enhances molecular mediators of neuroplasticity and subsequent functional recovery after ischemic stroke in rats. Mol Neurobiol 2015;51:1542-53.

57. Thomas T, Miners S, Love S. Post-mortem assessment of hypoperfusion of cerebral cortex in Alzheimer's disease and vascular dementia. Brain 2015;138:1059-69.

58. Ando H, Zhou J, Macova M, Imboden H, Saavedra JM, Angiotensin II AT1 receptor blockade reverses pathological hypertrophy and inflammation in brain microvessels of spontaneously hypertensive rats. Stroke 2004;35:1726-31.

59. Alemi M, Gaiteiro C, Ribeiro CA, Santos LM, Gomes JR, Oliveira $\mathrm{SM}$, et al. Transthyretin participates in beta-amyloid transport from the brain to the liver- involvement of the low-density lipoprotein receptor-related protein 1? Sci Rep 2016;6.

60. González-Marrero I, Giménez-Llort L, Johanson CE, CarmonaCalero EM, Castañeyra-Ruiz L, Brito-Armas JM, et al. Choroid plexus dysfunction impairs beta-amyloid clearance in a triple transgenic mouse model of Alzheimer's disease. Front Cell Neurosci 2015;9.

61. Isono N, Imamura Y, Ohmura K, Ueda N, Kawabata S, Furuse M, et al. Transthyretin concentrations in acute stroke patients predict convalescent rehabilitation. J Stroke Cerebrovasc Dis 2017;26: 1375-82.

62. Torika N, Asraf K, Apte RN, Fleisher-Berkovich S. Candesartan ameliorates brain inflammation associated with Alzheimer's disease. CNS Neurosci Ther 2018;24:231-42.

63. Torika N, Asraf K, Danon A, Apte RN, Fleisher-Berkovich S. Telmisartan modulates glial activation: in vitro and in vivo studies. PLoS One 2016;11. 